\title{
Spherical Silicon/CNT/Carbon Composite Wrapped with Graphene as an Anode Material for Lithium-Ion Batteries
}

\author{
Min-Seon Shin ${ }^{1}$, Cheon-Kyu Choi ${ }^{1}$, Min-Sik Park ${ }^{2 *}$, and Sung-Man Lee ${ }^{1 *}$ \\ ${ }^{1}$ Department of Materials Science and Engineering, Kangwon National University, Chuncheon, Gangwon-Do, 24341, \\ Republic of Korea \\ ${ }^{2}$ Department of Advanced Materials Engineering for Information and Electronics, Integrated Education Institute for Fron- \\ tier Science \& Technology (BK21 Four), Kyung Hee University, 1732 Deogyeong-daero, Giheung-gu, Yongin 17104, Republic of \\ Korea
}

\begin{abstract}
The assembly of the micron-sized $\mathrm{Si} / \mathrm{CNT} /$ carbon composite wrapped with graphene (SCG composite) is designed and synthesized via a spray drying process. The spherical SCG composite exhibits a high discharge capacity of $1789 \mathrm{mAh} \mathrm{g}^{-1}$ with an initial coulombic efficiency of $84 \%$. Moreover, the porous architecture of SCG composite is beneficial for enhancing cycling stability and rate capability. In practice, a blended electrode consisting of spherical SCG composite and natural graphite with a reversible capacity of $\sim 500 \mathrm{mAh} \mathrm{g}^{-1}$, shows a stable cycle performance with high cycling efficiencies $(>99.5 \%)$ during 100 cycles. These superior electrochemical performance are mainly attributed to the robust design and structural stability of the SCG composite during charge and discharge process. It appears that despite the fracture of micro-sized Si particles during repeated cycling, the electrical contact of Si particles can be maintained within the SCG composite by suppressing the direct contact of Si particles with electrolytes.
\end{abstract}

Keywords : Graphite, Silicon, Composite, Anode, Lithium Ion Batteries

Received : 12 October 2021, Accepted : 19 October 2021

\section{Introduction}

With recent developments in electronic devices and electric vehicles, the development of advanced lithium-ion batteries (LIBs) with high energy density, high power density and stable cycling performance is crucial for the success of the related industries. Accordingly, extensive research has been done on developing highly reliable electrode materials for advanced LIBs [1-5]. The current graphite anode does not meet the growing demand for high energy density in LIBs because of its limited theoretical capacity of $372 \mathrm{mAh} \mathrm{g}^{-1}$. In contrast, silicon is considered as one of the most promising candidate owing to its high theoretical capacity of $3579 \mathrm{mAh} \mathrm{g}^{-1}\left(\mathrm{Li}_{15}\right.$ $\mathrm{Si}_{4}$ ). However, the practical application of $\mathrm{Si}$ is still

*E-mail address: smlee@kangwon.ac.kr, mspark@khu.ac.kr DOI: https://doi.org/10.33961/jecst.2021.01004

This is an open-access article distributed under the terms of the Creative Commons Attribution Non-Commercial License (http://creativecommons.org/licenses/by-nc/4.0) Attribution Non-Commercial License (http://creativecommons.org/licenses/by-nc/4.0)
which permits unrestricted non-commercial use, distribution, and reproduction in any which permits unrestricted non-commercial use, distri
medium, provided the original work is properly cited. restricted by the following drawbacks: (1) large volume changes induced by charge (lithiation)-discharge (de-lithiation) process, which cause an electrical contact loss with continuous formation and growth of solid electrolyte interphase (SEI); (2) poor electrical conductivity, resulting in poor cycling performance and rate capability [6-9].

To overcome these problems, substantial research has been conducted for effectively accommodating the large volume changes and enhancing the electrical conduction of Si during cycling. According to the comprehensive overview on recent efforts for developing highly reliable Si-based anode materials [1015], much attentions have been devoted to the design of $\mathrm{Si} /$ Carbon composites, thanks to many desirable features of carbon, such as abundance, high electrical conductivity, light weight and good compatibility with various electrolytes. It is also recognized that the utilization of nanoscale Si particles can significantly relieve the mechanical strain induced by the large volume change without cracking and thus improve 
the cycle performance of Si-based anode materials. However, considering that Si nanoparticles are costly, it is crucial, from a commercial viewpoint, to utilize a low-cost material, such as ball-milled Si particles.

In general, the size of Si particles is very critical because Si particles larger than $150 \mathrm{~nm}$ suffer from significant particle cracking during lithiation-delithiation $[16,17]$. The cracking would cause significant loss of electrical contact and extensive electrolyte decomposition at the interface between $\mathrm{Si}$ and electrolyte forming additional SEI, leading to a deterioration of electrochemical performances. Unfortunately, the size of most ball-milled Si particles is larger than the above mentioned critical size of $150 \mathrm{~nm}$. Therefore, to utilize the Si particles larger than $150 \mathrm{~nm}$ as active materials, it is essential that the $\mathrm{Si} / \mathrm{C}$ composites should be designed to maintain electrical contact of Si particles and prevent the direct contact of $\mathrm{Si}$ particles with electrolytes, even though the Si particles are cracked during charge-discharge process.

Recently, several structural designs of $\mathrm{Si} / \mathrm{C}$ composites using submicron Si have been suggested; these studies have shown that graphene or reduced graphene oxide (RGO) is highly effective for constructing conductive network by encapsulating $\mathrm{Si}$ particles to improve the electrochemical performance of submicron Si [18-22]. In addition, carbon nanotubes (CNTs) have been used to form a three-dimensional (3D) porous conductive network for $\mathrm{Si} / \mathrm{C}$ composites owing to their excellent electrical conductivity and mechanical flexibility [23-25]. Herein, we report a spherical $\mathrm{Si} / \mathrm{C}$ composite, in which micron-sized Si/CNT/carbon composites wrapped with graphene (SCG composite) are assembled via a spray drying process. The distinctive architecture of SCG composites offers excellent cycling stability and rate capability, and it also ensures a stable cycling performance of the blended electrode with natural graphite.

\section{Experimental}

\subsection{Material synthesis}

The Si particles (bm-Si) was prepared by a ball milling of industrial Si waste using a high-speed planetary mill (PULVERISETTE 7). Multi-walled CNTs and graphene oxide (GO, GO-V30, STANDARD GRAPHENE, Korea) were used during the synthesis. The fabrication process for the assembly of the bm-Si/CNT/carbon composites wrapped with graphene (SCG composite) is as follows. The bm-Si and CNTs were dispersed in a petroleum pitch dissolved in tetrahydrofuran (THF) solution, followed by THF evaporation using a vacuum evaporator, and mixing with GO dispersed in a gum arabic (GA) dissolved water. Then, the GO was reduced by adding hydrazine with a ratio of $3 \mathrm{~mL} / \mathrm{GO} 100 \mathrm{mg}$ and mechanical mixing at $95^{\circ} \mathrm{C}$, and was subsequently spray dried. The resultant composite precursor was heat treated at $1000^{\circ} \mathrm{C}$ for 1 hour in an argon atmosphere.

\subsection{Characterization}

The morphologies and microstructures of composites were investigated using field emission-scanning electron microscopy (FE-SEM, HITACHI S-4300) and high-resolution transmission electron microscopy (HRTEM, JEOL JEM-2100F) coupled with energy dispersive X-ray spectroscopy (EDS). The cross-sectional SEM and TEM analyses were performed using a focused ion beam (FIB) system (FEI COMPANY, NOVA 200). The particle size distribution was investigated by a particle size analyzer (Mastersizer 2000, Malvern). The electrode swelling was also measured by a micrometer (HST30.4, Wellcos Co., Ltd).

\subsection{Electrochemical measurement}

Electrodes for SCG composite were fabricated by pasting an aqueous slurry containing $80 \mathrm{wt} \%$ active material, $5 \mathrm{wt} \%$ carbon black, and $15 \mathrm{wt} \%$ poly (acrylic acid) (PAA) as a binder, on to a copper foil (20 $\mu \mathrm{m}$ in thickness). The electrodes were then dried at $180^{\circ} \mathrm{C}$ for $12 \mathrm{~h}$ in vacuum and were subsequently pressed. A blended electrode with a mix of SCG composite and natural graphite $\left(\mathrm{D}_{50}=16 \mu \mathrm{m}\right.$, POSCO Chemical Co. Ltd, Korea) contains 95 wt $\%$ active material, $1 \mathrm{wt} \%$ carbon black, and $4 \mathrm{wt} \%$ binder, styrene butadiene(SBR)/carboxymethyl cellulose (CMC), 2:1 by weight). The 2032 coin-type half-cells were assembled in an Ar-filled glovebox, in which lithium foil was used as both the reference and counter electrodes. The mass loading of the active material was $\sim 5 \mathrm{mg} \mathrm{cm}^{-2}$. The electrolyte used was 1 $\mathrm{M} \mathrm{LiPF}_{6}$ in a mixture of ethylene carbonate (EC) and diethyl carbonate (DEC) (1:1 by volume) with $10 \mathrm{wt} \%$ fluoroethylene carbonate (FEC). The cells were charged (lithiated) and discharged (delithiated) 
between 0.01 and $2.0 \mathrm{~V}$ at $30^{\circ} \mathrm{C}$. For initial formation process, the cells were charged in constant currentconstant voltage mode ( $\mathrm{CC}-\mathrm{CV}$ mode) and discharged at a constant current (CC) of $100 \mathrm{~mA} \mathrm{~g}^{-1}$ for 2 cycles. The cyclability and rate capability were measured after the initial formation process for 2 cycles.

\section{Results and discussion}

Fig. 1 illustrates a synthesis process of spherical SCG composite via a spray drying process. The bmSi particles, CNTs and GO sheets were used as starting materials for assembling the SCG composite (Fig. S1). First of all, irregular shaped bm-Si particles and CNTs with a mean diameter of $15 \mathrm{~nm}$ were thoroughly mixed. The mixture of bm-Si particles and CNTs was dispersed in a petroleum pitch dissolved in THF solution and then wrapped GO sheets by a spray drying, followed by a carbonization process. Finally, the spherical SCG composite with the average particle size of $13 \mu \mathrm{m}$ was obtained. Note that bm-Si has a bimodal particle size distribution with $\mathrm{D} 10=0.18 \mu \mathrm{m}, \mathrm{D} 50=0.69 \mu \mathrm{m}$ and D90 $=$
$1.9 \mu \mathrm{m}$. The particle size distribution of starting materials and SCG composite are compared in Fig. S2.

Fig. 2 presents top-view and cross-sectional FESEM images of spherical SCG composite combined with corresponding EDS elemental mapping results for $\mathrm{Si}$ and $\mathrm{C}$, showing that bm-Si particles are uniformly dispersed in the network of CNTs inside the particle. The microstructure of the SCG composite was further characterized using TEM in Fig. 3. The spherical SCG composite has a porous structure (Fig 3a), in which bm-Si particles and CNTs are forming 3D networks inside the particle (Fig. 3b). It is confirmed that the SCG composite particle is coated with reduced graphene oxide (RGO) sheet with approximately $5 \mathrm{~nm}$ in thickness (Fig. 3c, the HR-TEM image for R2 region of Fig. S3). Corresponding EDS elemental mapping results also confirm that bm-Si particles are surrounded by CNTs (Fig. S4). Fig. $3 \mathrm{~d}$ shows the $\mathrm{N}_{2}$ adsorption and desorption isotherm for the SCG composite. The Brunauer-Emmett-Teller (BET) specific surface area of the SCG composite was calculated to be $6.38 \mathrm{~m}^{2} \mathrm{~g}^{-1}$. The pore-size distribution (inset of Fig. 3d) reveals
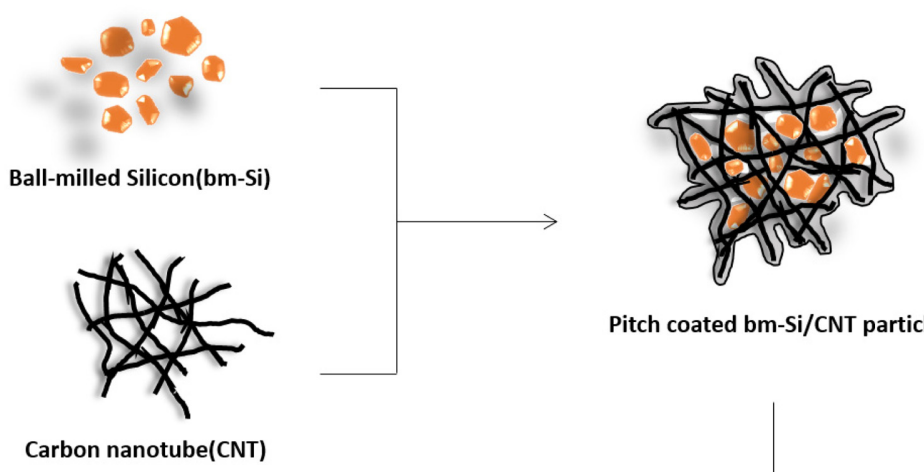

Pitch coated bm-Si/CNT particle
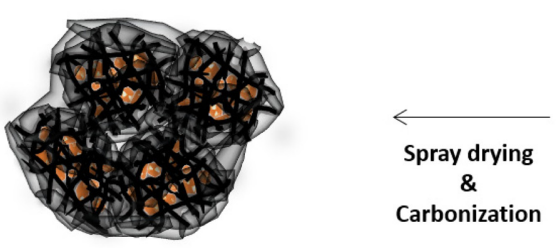

bm-Si/CNT/Carbon composite particle

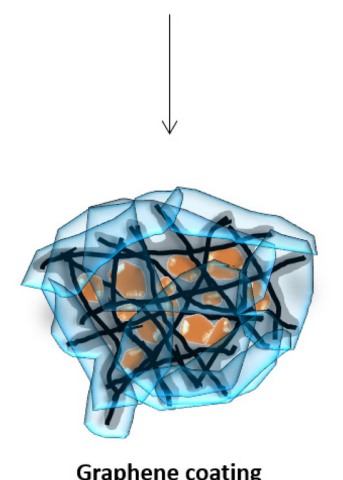

Fig. 1. Schematic illustration of the synthesis process of spherical SCG composite via a spray drying and carbonization process. 

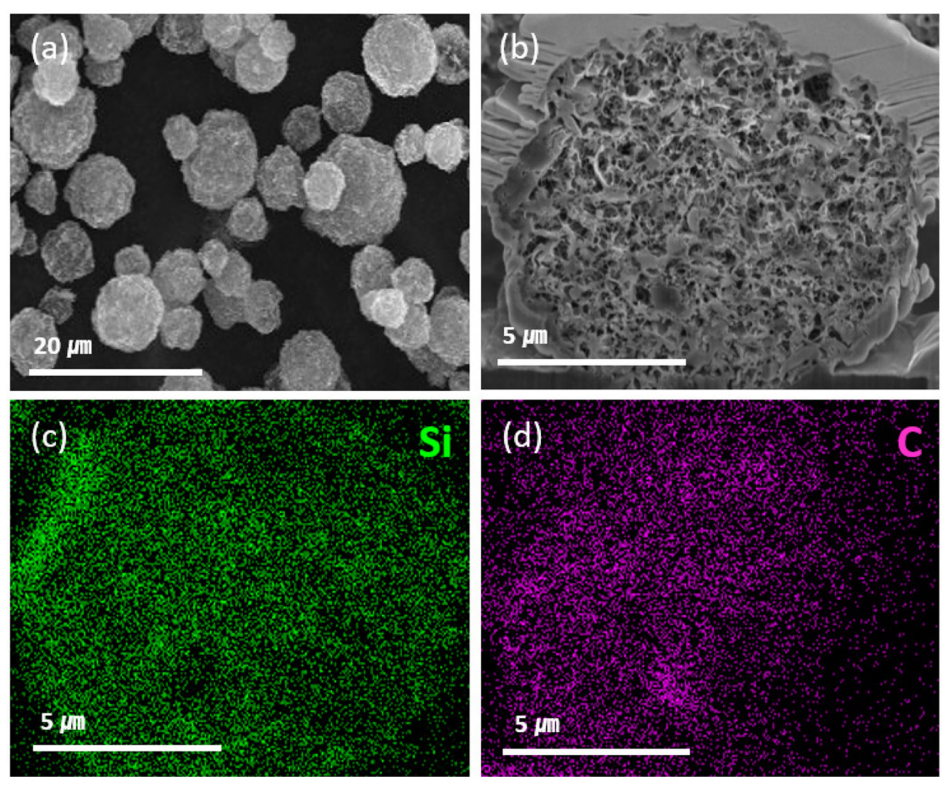

Fig. 2. (a) Top-view and (b) cross-sectional FESEM images of spherical SCG composite particles. Corresponding EDS elemental mapping results for (c) $\mathrm{Si}$ (green) and (d) $\mathrm{C}$ (purple).
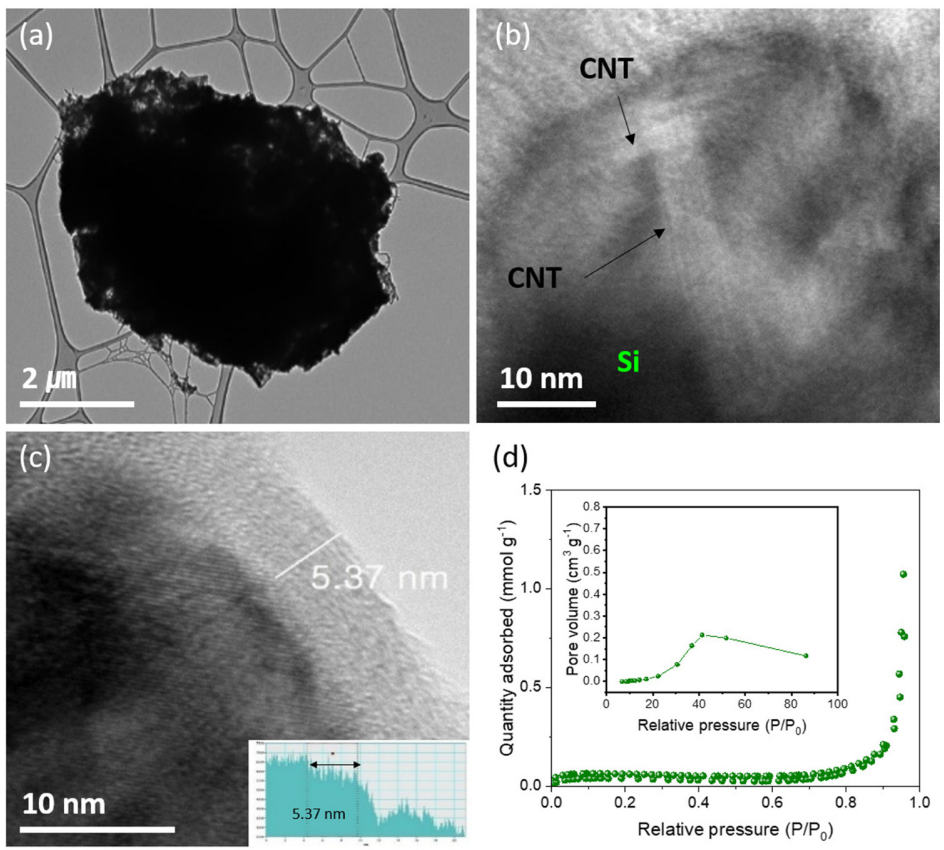

Fig. 3. (a) TEM image of SCG composite particle at low magnification with the grid of TEM holder in view. (b) High-resolution TEM image and (c) the position of intensity profile on the edge line of SCG composite. (d) $\mathrm{N}_{2}$ adsorption and desorption isotherm for the SCG composite (inset showing the pore size distribution curve).

that the SCG composite contains mesopores lying between 2 to $50 \mathrm{~nm}$ and macropores exceeding $50 \mathrm{~nm}$ in diameter.

The electrochemical performance of the SCG composite as anode material for LIBs was evaluated. Fig. 4a shows the charge-discharge curves of the first two cycles for formation process. The SCG composite electrode exhibited a discharge capacity of $1789 \mathrm{mAh} \mathrm{g}^{-1}$ with an initial coulombic efficiency of $84 \%$. After the two formation cycles, the cycle performance of the SCG composite anode was tested at a current density of $0.2 \mathrm{C}$ (Fig. 4b), in which the capacity was stabilized at $1741 \mathrm{mAh} \mathrm{g}^{-1}$ after 25 cycles with a slight decrease in capacity $(0.8 \%$ compared to the capacity at stabi- 

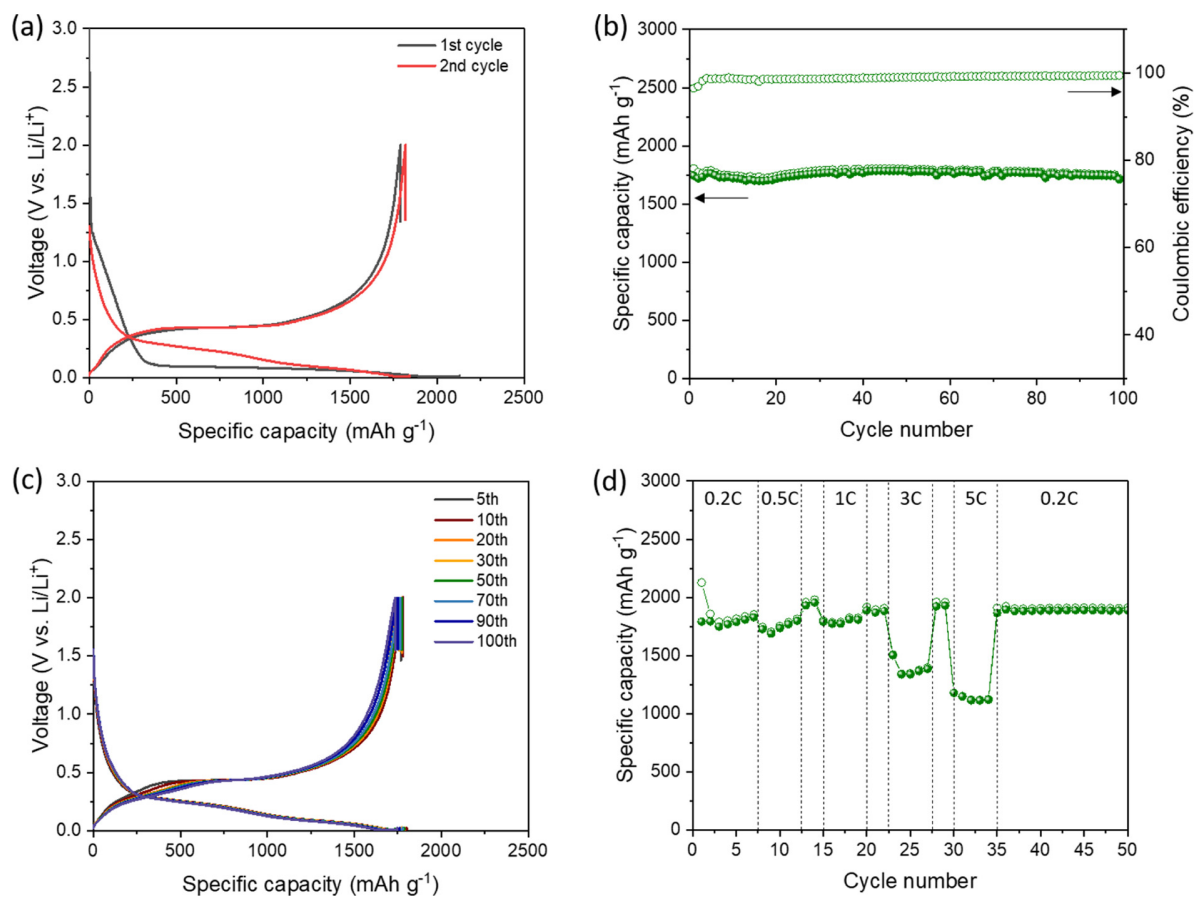

Fig. 4. (a) Galvanostatic charge-discharge curves of SCG composite electrode at the first two cycles for formation process. (b) cycle performance of SCG composite electrode during 100 cycles with (c) corresponding charge-discharge curves at different cycles. (d) Charge rate capability of SCG composite electrode at various current densities of $0.2,0.5,1,3$, and $5 \mathrm{C}$ $\left(1 \mathrm{C}=1000 \mathrm{~mA} \mathrm{~g}^{-1}\right)$.

lized cycles) was seen at the initial stages of cycling. The latter phenomenon may be attributed to the activation of the SCG composite with structure enveloped by graphene. The coulombic efficiency was $\sim 99 \%$ in the initial 30 cycles but maintained over $99.5 \%$ after 50 cycles. The enhanced cycling performance is verified by the steady chargedischarge curves during 100 cycles as shown in Fig. $4 c$. This indicates that the SCG composite has high structural stability and thus the mechanical integrity of the electrodes can be maintained during cycling. The structure stability of the SCG composite electrode can be examined by the morphological change during cycling. After 50 cycles, there are some cracks on the surface. However, when the SEI film on the surface is removed, no apparent cracks can be observed and the surface morphology looks similar to that before cycling (Fig. S5).

The charge rate capability of the SCG composite electrode was evaluated at current densities ranging from 0.5 to $5 \mathrm{C}$, where the discharge was performed at $0.1 \mathrm{C}$. As shown in Fig. 4d the capacity was $1338 \mathrm{mAh}$ $\mathrm{g}^{-1}$ at $3 \mathrm{C}$ and $1114 \mathrm{mAh} \mathrm{g}^{-1}$ at $5 \mathrm{C}$, corresponding to 72.9 and $60.7 \%$ of its capacity at $0.2 \mathrm{C}$ during stabilized cycling, respectively. It also reveals that the SCG composite electrode recovers its capacity and remains highly stable when tested at $0.2 \mathrm{C}$ after cycling at high rates up to $5 \mathrm{C}$. The excellent rate capability of the SCG composite electrode may be attributed to the enhanced electrical conduction, owing to SCG composite architecture, enabling the Si particles to contact with the network of CNT/carbon.

For more detailed information on the cycling behavior, the differential capacity $(\mathrm{dQ} / \mathrm{dV})$ plots of the SCG composite electrode at different cycle number are presented in Fig. 5a. First, the intensities and positions of peaks in the lithiation curves undergo minor change for 100 cycles, which shows the complete lithiation without a significant polarization during cycling. In contrast, the delithiation profiles show noticeable changes with prolonged cycling. An intense delithiation peak appears at $\sim 0.43 \mathrm{~V}$ for initial cycles, which is related 
to the formation of crystalline $\mathrm{Li}_{15} \mathrm{Si}_{4}$ [26-28]. The corresponding peak continues to decrease in the intensity and broaden upon cycling, as shown in Fig. 5. It is known that the well-defined peak at $\sim 0.43 \mathrm{~V}$ is observed with micron-sized Si particles [29-31],

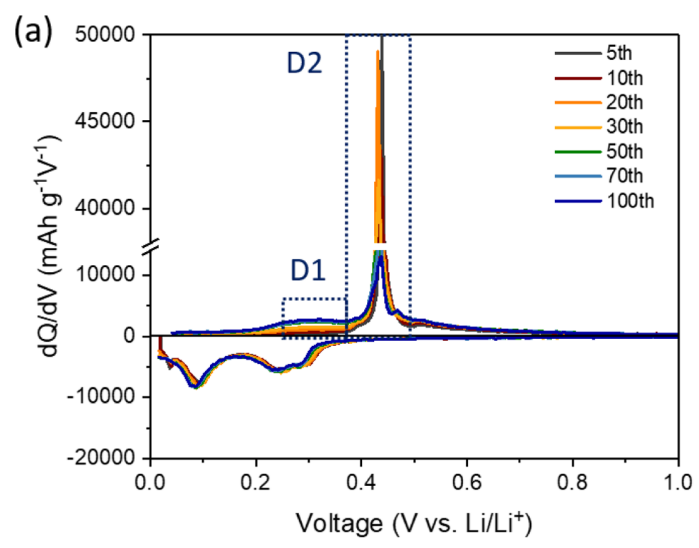

(b)
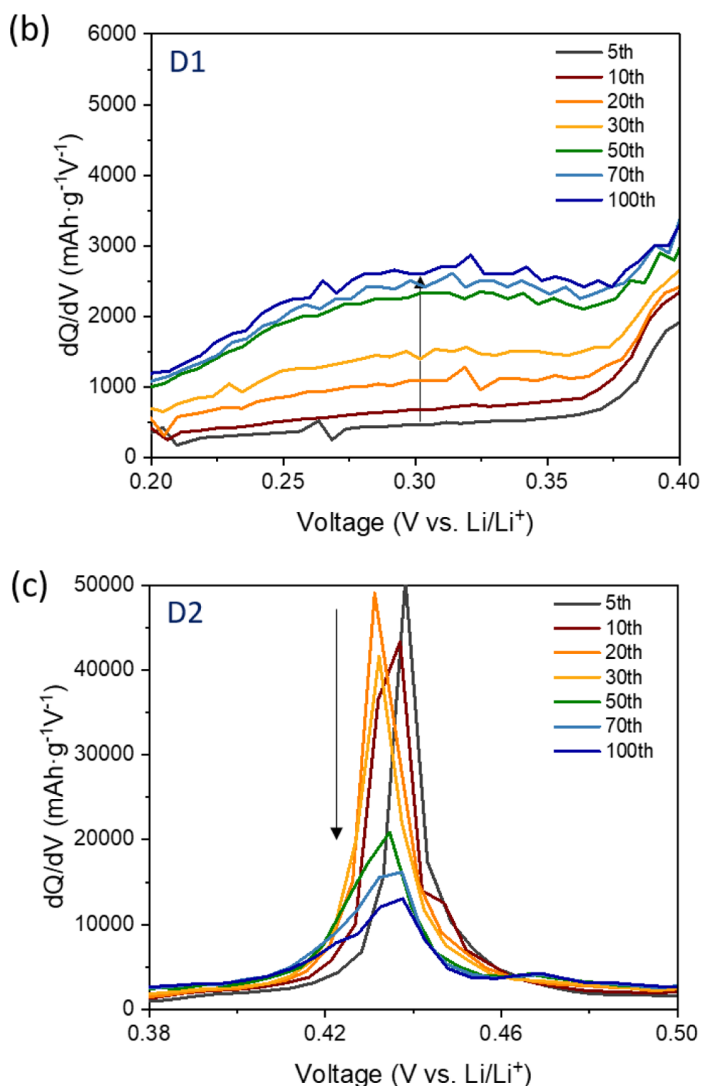

Fig. 5. (a) Differential capacity plots of SCG composite electrode at different cycles. Magnified differential profiles of region (b) D1 and (c) D2. while in the case of nanoscale $\mathrm{Si}$, the corresponding peak is broad [27,32,33]. Moreover, during cycling, micron-sized Si particles are broken into nanoscale $\mathrm{Si}$ particles, as reported previously [16-18,20]. An additional broad peak at $\sim 0.3 \mathrm{~V}$, ascribed to the delithiation from amorphous phase $[27,34,35]$, is

(a)

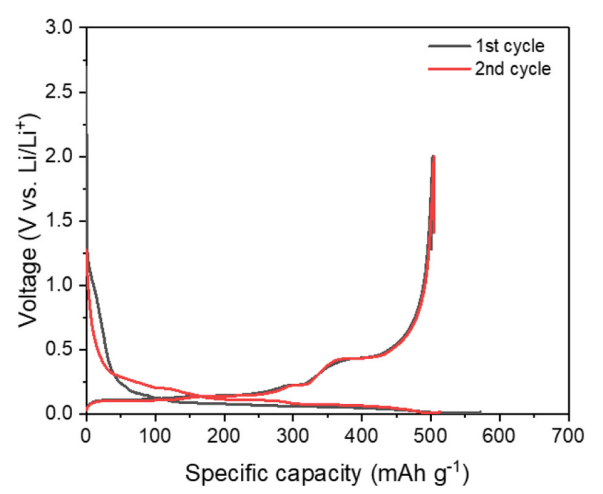

(b)

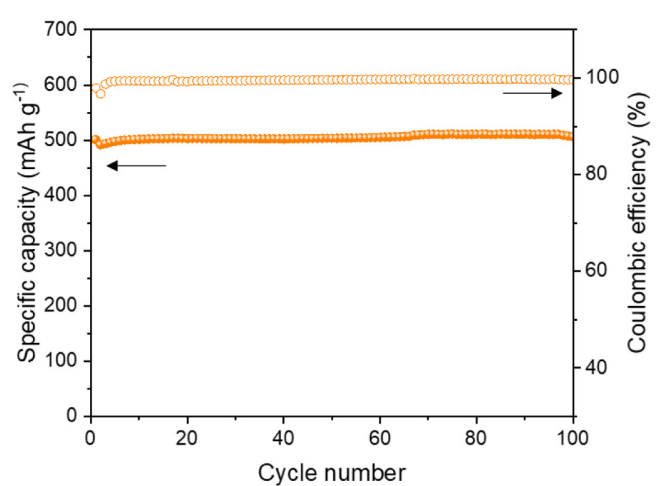

(c)

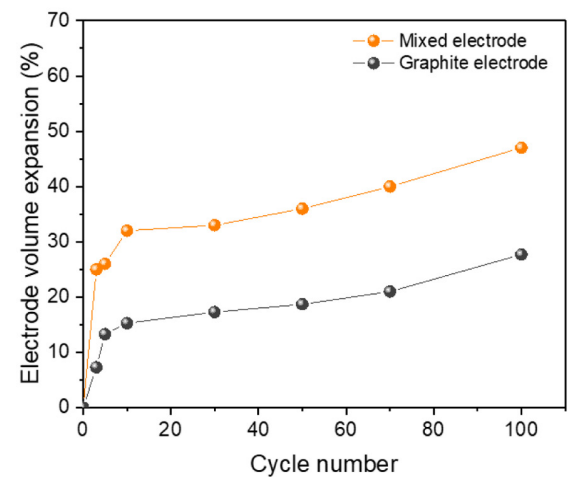

Fig. 6. Electrochemical properties of a blended electrode with $10 \mathrm{wt} \%$ of spherical SCG composite and $90 \mathrm{wt} \%$ natural graphite. (a) galvanostatic charge-discharge curves at the first two cycles and (b) cycle performance and coulombic efficiencies during cycles. (d) Swelling rate of a blended electrode and natural graphite electrode. 
formed and the extent of the peak intensity increases upon cycling, as shown in Fig. 5b. It seems that the decrease in the peak at $\sim 0.43 \mathrm{~V}$ (Fig. 5c) is compensated by the increase in the broad peak at $\sim 0.3 \mathrm{~V}$, as inferred from the stable capacity retention. The results indicate that despite the Si particle cracking during cycling, the electrical contact of Si particles within the SCG composite is maintained and the direct contact of Si particles with electrolytes is prevented.

In general, to improve the energy density of LIBs, considering the large volume change of Si during cycling, a blended electrode consisting of Si-based anode material and graphite is preferred rather than using Si-based anode material only [36-41]. Fig. 6 shows the electrochemical performance of a blended electrode with $10 \mathrm{wt} \%$ of SCG composite and $90 \mathrm{wt} \%$ spherical natural graphite, targeting a capacity of $\sim 500 \mathrm{mAh} \mathrm{g}^{-1}$. In view of the practical application, the electrode was fabricated with an electrode density of $1.6 \mathrm{~g} \mathrm{~cm}^{-3}$ and by mixing $95 \mathrm{wt} \%$ active material, $1 \mathrm{wt} \%$ carbon black, and $4 \mathrm{wt} \%$ binder (SBR/CMC). The galvanostatic charge-discharge curves for the first two cycles are displayed in Fig. 6a. The first discharge capacity and the initial coulombic efficiency were $501 \mathrm{mAh} \mathrm{g}^{-1}$ and $87.5 \%$, respectively, which are similar to those calculated from SCG composite (10 wt\%) and spherical natural graphite $(90 \mathrm{wt} \%)$. The cycling performance of the blended electrode is shown in Fig. 6b. It demonstrates negligible capacity fade in the 100 cycles and high cycling efficiency. The swelling of electrode was measured in the delithiated state as a function of cycle number. The swelling ratio of the blended electrode is compared with that of the graphite electrode, as shown in Fig. 6c. The main expansion of the blended electrode occurs during initial 10 cycles, and during subsequent cycles the thickness changes were much milder. It is worth noting that the gap between the swelling ratio of the blended electrode and the graphite electrode appears to be similar during cycling, which implies the outstanding structural stability of the blended electrode. The electrode microstructures before cycling and after 50 cycles were investigated to verify the structural stability of the blended electrode (Fig. 7). The cross-sectional SEM images show that the structural integrity of the electrode, especially of the SCG composite, is maintained even after 50 cycles without significant growth of SEI film.

\section{Conclusions}

A spherical $\mathrm{Si} / \mathrm{C}$ composite was successfully synthesized by assembling graphene wrapped bm-Si /CNT/carbon composites through a spray drying process. The robust design and structural stability of spherical SCG composite allowed outstanding cycling stability and superior rate capability. The feasibility of SCG composite was further examined by constructing a blended electrode, consisting of SCG composite and natural graphite. The blended electrode showed a capacity of $\sim 500 \mathrm{mAh} \mathrm{g}^{-1}$, maintaining stable cycle performance up to 100 cycles with high cycling efficiencies $(>99.5 \%)$. It is
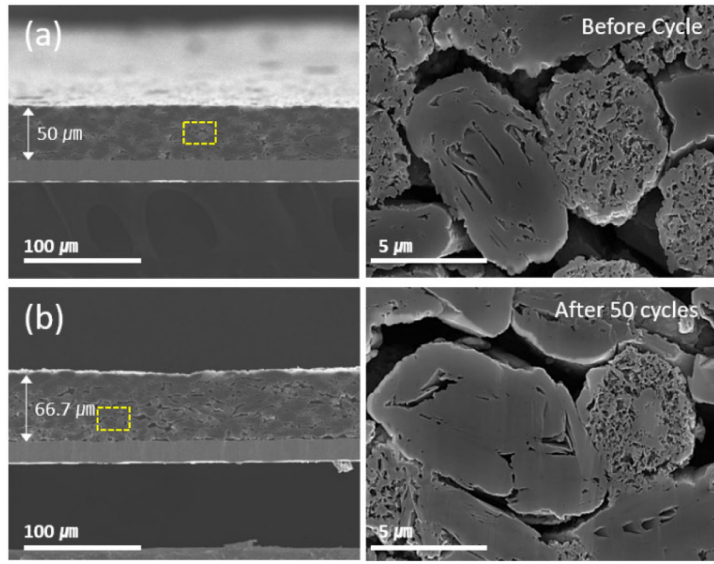
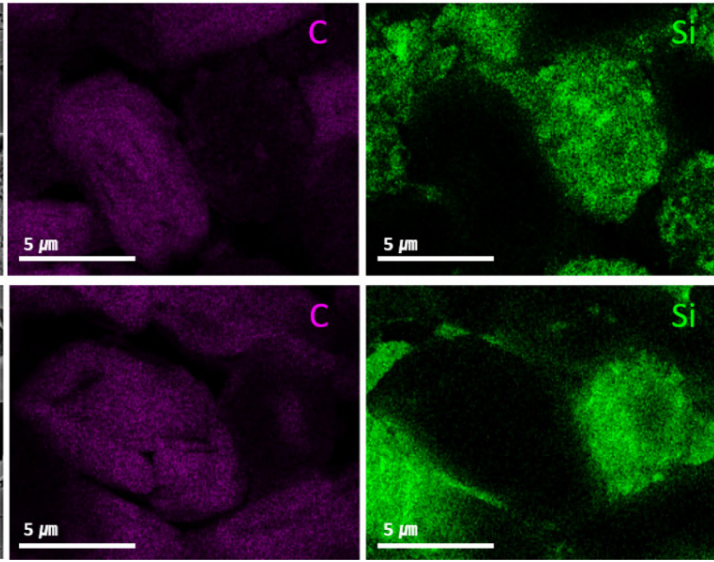

Fig. 7. Cross-sectional SEM images of the blended electrode (a) before and (b) after 50 cycles with magnified images and corresponding EDS elemental mapping results for $\mathrm{C}$ (purple) and $\mathrm{Si}$ (green). 
because undesirable capacity loss can be minimized by effectively accommodating the large volume changes and suppressing the electrical contact loss of $\mathrm{Si}$ in the composite. We believe that our approach would provide a practical solution for developing advanced anode materials for high-energy LIBs.

\section{Supporting Information}

Supporting Information is available at https:// doi.org/10.33961/jecst.2021.01004

\section{References}

[1] J. M. Tarascon, M. Armand, Nature, 2001, 414, 359367.

[2] V. Etacheri, R. Marom, R. Elazari, G. Salita, D. Aurbach, Energy Environ. Sci., 2011, 4(9), 3243-3262.

[3] J. Lu, Z. Chen,F. Pan, Y. Cui, K. Amine, Electrochem. Energy Rev., 2018, 1(1), 35-53.

[4] R. Schmuch, R. Wagner, G. Hörpel, T. Placke, M. Winter, Nat. Energy, 2018, 3(4), 267-278.

[5] J. Asenbauer, T. Eisenmann, M. Kuenzel, A. Kazzazi, Z. Chen, D. Bresser, Sustainable Energy Fuels, 2020, 4(11), 5387-5416.

[6] A. Casimir, H. Zhang, O. Ogoke, J. C. Amine, J. Lu, G. $\mathrm{Wu}$, Nano Energy, 2016, 27, 359-76.

[7] T. Yoon, C. C. Nguyen, D. M. Seo, B. L. Lucht, J. Electrochem. Soc., 2015, 162(12), A2325.

[8] P. G. Bruce, B. Scrosatti, J. M. Tarascon, Angew. Chem. Int. Ed., 2008, 47(16), 2930-2946.

[9] R. Yi, F. Dai, M. L. Gordin, S. R. Chen, D. H. Wang, Adv. Energy Mater., 2013, 3(3), 295-300.

[10] X. Li, M. Zhang, S. Yuan, C. Lu, ChemElectroChem, 2020, 7(21), 4289-4302.

[11] Y. Jin, B. Zhu, Z. Lu, N. Liu, J. Zhu, Adv. Energy Mater., 2017, 7(23), 1700715.

[12] X. Liu, X. Zhu, D. Pan, R. Soc. Open Sci., 2018, 5(6), 172370.

[13] F. Dou, L. Shi, G. Chen, D. Zhang, Electrochem. Energy Rev., 2019, 2(1), 149-198.

[14] X. Zhao, V. P. Lehto, Nanotechnology, 2021, 32, 042002 .

[15] J. Asenbauer, T. Eisenmann, M. Kuenzel, A. Kazzazi, Z. Chen, D. Bresser, Sustainable Energy Fuels, 2020, 4(11), 5387-5416.

[16] H. Kim, M. Seo, M. Park, J. Cho, Angew. Chem. Int. Ed., 2010, 49(12), 2146-2149.

[17] S. W. Lee, M. T. McDowell, J. W. Choi, Y. Cui, Nano Lett., 2011, 11(7), 3034-3039.

[18] Y. Li, K. Yan, H. -W. Lee, Z. Lu, N. Liu, Y. Cui, Nat. Energy, 2016, 1(2), 1-9
[19] X. Zhang, R. Guo, X. Li, L. Zhi, Small, 2018, 14(24), 1800752.

[20] B. Lee, T. Liu, S. K. Kim, H. Chang, K. Eom, L. Xie, S. Chen, H. D. Jang, S. W. Lee, Carbon, 2017, 119, 438.

[21] X. Han, H. Chen, Z. Zhang, D. Huang, J. Xu, C. Li, S. Chen, Y. Yang, J. Mater. Chem. A, 2016, 4(45), 1775717763.

[22] X. Liu, D. Chao, Q. Zhang, H. Liu, H. Hu, J. Zhao, Y. Li, Y. Huang, J. Lin, Z. X. Shen, Sci. Rep., 2015, 5(1), $1-10$.

[23] B. Liu, P. Soares, C. Checkles, Y. Zhao, G. Yu, Nano Lett., 2013, 13(7), 3414-3419.

[24] G. D. Park, J. H. Choi, D. S. Jung, J.S. Park, Y. C. Kang, J. Alloy Comp., 2020, 821, 153224.

[25] Y. Li, G. Xu, L. Xue, S. Zhang, Y. Yao, Y. Lu, O. Toprakci, X. Zhang, J. Electrochem. Soc., 2013, 160(3), A528.

[26] T. D. Hatchard, J. R. Dahn, J. Electrochem. Soc., 2004, 151(6), A838.

[27] W. J. Zhang, J. Power Sources, 2011, 196(3), 877-885.

[28] J. Li, A. Smith, R. J. Sanderson, T. D. Hatchard, R. A. Dunlap, J. R. Dahn, J. Electrochem. Soc., 2009, 156(4), A283.

[29] J. H. Ryu, J. W. Kim, Y. E. Sung, S. M. Oh, Electrochem. Solid-State Lett., 2004, 7(10), A306.

[30] M. N. Obrovac, L. Christensen, Electrochem. Solid-State Lett., 2004, 7(5), A93.

[31] J. Li, J. R. Dahn, J. Electrochem. Soc., 2007, 154(3), A156.

[32] J. Saint, M. Morerette, D. Larcher, L. Laffont, S. Beattie, J. P. Pérès, D. Talaga, M. Couzi, J. M. Tarascon, $A d v$. Funct. Mater., 2007, 17(11), 1765-1774.

[33] H. Li, X. Huang, L. Chen, Z. Wu, Y. Liang, Electrochem. Solid-State Lett., 1999, 2(11), 547.

[34] M. Wetjen, D. Pritzl, R. Jung, S. Solchenbach, R. Ghadimi, H. A. Gasteiger, J. Electrochem. Soc., 2017, 164(12), A2840.

[35] F. Jeschull, Y. Surace, S. Zürcher, M. E. Spahr, P. Novák, S. Trabesinger, Electrochim. Acta, 2019, 320, 134602.

[36] V. L. Chevrier, L. Liu, D. B. Le, J. Lund, B. Molla, K. Reimer, L. J. Krause, L. D. Jensen, E. Figgemeier, K. W. Eberman, J. Electrochem. Soc., 2014, 161(5), A783.

[37] X. Li, P. Yan, X. Xiao, J. H. Woo, C. Wang, J. Liu, J. G. Zhang, Energy Environ. Sci., 2017, 10(6), 1427-1434.

[38] J. B. Park, J. S. Ham, M. S. Shin, H. K. park, Y. J. lee, S. M. Lee, J. Power Sources, 2015, 299, 537.

[39] S. S. Suh, W. Y. Yoon, D. H. Kim, S. U. Kwon, J. H. Kim, Y. U. Kim, C. U. Jeong, Y. Y. Chan, S. H. Kang, J. K. Lee, Electrochim. Acta., 2014, 148, 111-117.

[40] H. Jung, K. S. Kim, S. E. Park, J. Park, Eletrochim. Acta, 2017, 245, 791-795.

[41] Z. Du, R. A. Dunlap, M. N. Obrovac, J. Electrochem. Soc., 2014, 161(10), A1698. 